\title{
INVESTIGANDO A OCUPAÇÃO DAS “TRIBOS” NOS ESPAÇOS DE LAZER DA ORLA DE ATALAIA EM ARACAJU/SE
}

Recebido em: 12/09/2011

Aceito em: 21/03/2012

$$
\begin{array}{r}
\text { Paula Aragão }{ }^{1} \\
\text { Universidade Federal de Santa Catarina } \\
\text { Florianópolis - SC - Brasil } \\
\text { Luciana Carolline Pina Garcia }{ }^{2} \\
\text { Unit } \\
\text { Aracaju - SE - Brasil } \\
\text { Cristiano Mezzaroba } \\
\text { Universidade Federal de Santa Catarina } \\
\text { Universidade Federal de Sergipe } \\
\text { Aracaju - SE - Brasil }
\end{array}
$$

RESUMO: Esta pesquisa integra o Projeto Orla, que estuda os espaços públicos de lazer da Orla de Atalaia, Aracaju/SE, a qual reúne um número diversificado de espaços destinados às práticas corporais de esporte e lazer, fato que atrai pessoas de diferentes gostos e estilos. Considerando a localização e estrutura, buscou-se identificar os interesses dos grupos em relação ao espaço e seus equipamentos. Na pesquisa de caráter qualitativo e de cunho descritivo foram utilizados como instrumentos de coleta, a entrevista semi-estruturada e o diário de campo. Os resultados demonstram que a acessibilidade e a qualidade das estruturas são fatores primordiais de interesse às "tribos".

PALAVRAS CHAVE: Grupo Social. Esportes. Atividades de Lazer.

\section{INVESTIGATING THE OCCUPATION OF THE SO CALLED “TRIBES" IN LEISURE SPACES OF THE SEASHORE OF ARACAJU/SE}

ABSTRACT: This research is part of Project Orla that studies public spaces for leisure on the Atalaia seafront in the city of Aracaju/SE, which brings together a diverse number of spaces intended for bodily practices of sport and leisure, attracting people of different tastes and styles. Considering the location and structure, we sought to identify the interests of groups in relation to the space and the equipment. In qualitative/descriptive research were used as data collection instruments, the

\footnotetext{
${ }^{1}$ Mestranda em Educação Física pela UFSC.

${ }^{2}$ Licenciada em Educação Física pela Unit.

${ }^{3}$ Mestre em Educação Física pela UFSC. Professor DEF/CCBS/UFS.
} 
Semistructured interview and the Field Journal. The results show that the accessibility and the quality of structures are major factors of interest to the "tribes".

KEYWORDS: Social Group. Sports. Leisure Activities.

\section{INTRODUÇÃO}

Esta investigação realizada no complexo de lazer "Orla de Atalaia" em AracajuSE integra uma pesquisa construída pelo grupo de estudos Observatório da Mídia Esportiva da Universidade Federal de Sergipe ${ }^{4}$, denominada de Projeto Orla ${ }^{5}$, a qual tem como foco de análise a investigação dos equipamentos de lazer e esporte, bem como, a utilização desses espaços que constituem a Orla de Atalaia em Aracaju/SE. Neste contexto iniciamos aqui a discussão do segundo eixo da pesquisa na intenção de investigar a ocupação, pela população, dos espaços de esporte e lazer existentes.

A Orla de Atalaia $^{6}$ reúne em toda sua extensão um número diversificado de espaços destinados às práticas corporais de lazer, a exemplo da caminhada, da corrida e da patinação, além dos espaços específicos destinados a algumas práticas esportivas como basquetebol, voleibol, futebol, tênis e skate. Essa diversificação proporciona o encontro entre as pessoas que frequentam o complexo caracterizando a Orla como um ponto de encontro do que se pode chamar de diversidade de grupos sociais, aqui denominados de tribos ${ }^{7}$. Essas "tribos" foram selecionadas de acordo com o interesse da

\footnotetext{
${ }^{4}$ O Grupo de Estudo congrega os pilares da Universidade no tocante ao ensino, pesquisa e extensão. Desenvolve estudos no campo da Educação Física, Esporte e Mídia e principalmente, a relação mídiaeducação, tem sido foco de nossos debates e possibilidades.

${ }^{5}$ O Projeto foi elaborado pensando em três eixos centrais: 1. Os Espaços Públicos de Lazer; 2. As "tribos" que freqüentam a Orla; 3. A gestão de políticas públicas de/para a Orla de Atalaia.

${ }^{6} \mathrm{O}$ espaço público Orla de Atalaia foi construído em duas etapas: $1^{\text {a }}$ etapa, Projeto Capital entregue em agosto de 1994; $2^{\text {a }}$ etapa Nova Orla de Atalaia - 2o trecho, entregue em março de 2005 (http://www.orladeatalaia.com.br/nossaorla.htm). Eventualmente, no decorrer do trabalho o nome "orla" fará referência a este espaço público.

${ }^{7}$ Conceito utilizado dos estudos de Machado Pais (2004), esclarecido sem seguida. Mas inicialmente surgiu para impulsionar a pesquisa como uma denominação utilizada para os grupos que frequentam a Orla de Atalaia e por ocuparem espaços distintos e em horários diversificados.
} 
pesquisa, logo, foram escolhidos grupos que de alguma forma ocupavam os espaços para uma determinada prática esportiva de lazer ou não.

A palavra tribo se aplica a um grupo social com relativa ocupação espacial e que pode apresentar culturas próprias, isento de organização política ou qualquer forma da autoridade (FERREIRA, 2001). Esse termo, no presente texto, não será utilizado com sentido de "etiquetagem" da palavra, que comumente traduz um significado malfadado de pessoas marginalizadas. Aqui, ele não será atributo de taxadores do que lhes é indiferente ou fora do padrão habitual. Utilizaremos para esta pesquisa o sentido que Pais (2004) apresentou e caracterizou em seus estudos sobre os grupos de jovens brasileiros e portugueses, como forma de convivência geradora do sentimento de pertença, consequentemente de identidade.

Ao observar cada espaço de lazer ocupado na orla: quadras, pistas, parques, praças, entre outros, pode-se perceber a existência de características peculiares aos grupos frequentadores desses espaços, tanto no tocante às vestimentas, acessórios e linguagem, quanto aos estilos, uso de gírias, expressões e comportamentos. Características que expõem culturas diversas, formas de organização que geram nas pessoas uma identidade com o grupo e com o local que frequentam, além de um sentimento de pertença a ambos. Além disso, essa ligação ao local perpassa pelo atrativo que o próprio complexo de lazer apresenta e que move o interesse dos frequentadores em relação às pistas e quadras.

Mediante a análise do tempo de permanência, horários e dias de maior aglomeração é possível encontrar algumas tribos nos seus espaços específicos e delinear possíveis aspectos culturais, econômicos e sociais (englobando normas, valores e status) que caracterizam estes grupos, o que leva a um reconhecimento que pode ser 
compreendido pelos objetivos comum a todos, o de frequentar o espaço de lazer. Diante disso, buscamos identificar as tribos dentro do seu convívio, enfocando seus interesses em relação aos equipamentos que compõem o complexo público de lazer Orla de Atalaia.

Neste sentido, é válido ressaltar que algumas indagações geradoras nos ajudaram na construção do objetivo proposto, a saber: os fatores relevantes quanto à caracterização dos sujeitos e dos grupos aos quais pertencem (indumentária, linguagem, prática corporal escolhida); identificação de aspectos como acessibilidade, localização e estrutura que são oferecidos pelos espaços frequentados.

Mediante uma observação preliminar pode-se perceber que cada espaço possui suas próprias características, a exemplo dos escritos (frases, nomes, desenhos) encontrados nas pistas de skate, os quais esboçam uma linguagem e uma expressão peculiar. Diante dessa constatação procuramos entender o sentido dessa linguagem transmitida pelos atores/autores de cada tribo e como essas particularidades se relacionam com a organização e convivência do grupo.

O número cada vez maior de frequentadores nos espaços da Orla de Atalaia atrai olhares $^{8}$, inclusive o nosso. Por isso, este estudo vem proporcionar uma aproximação a novos contextos, instigando novas perspectivas em relação às chamadas tribos.

Partindo desse pressuposto, é possível dizer que a análise da pesquisa leva a um entendimento de que diferentes realidades passam despercebidas no cotidiano (friamente banalizado) de nossa sociedade e escondem as razões que

\footnotetext{
${ }^{8}$ Verifica-se que a Orla é considerada um espaço destinado ao turismo, às práticas esportivas e a empreendimentos artístico-culturais, seja no campo privado ou público e, portanto, atrai não somente a atenção daqueles que frequentam os seus espaços em busca de algum tipo de refúgio do cotidiano, mas também de pessoas que usufruem os espaços com vistas em objetivos econômicos e políticos, portanto, os olhares dos observadores se voltam em torno de cada acontecimento com a intenção entender melhor as relações que circundam os espaços de lazer na grande orla.
} 
"despretensiosamente" obrigam alguns grupos à não desfrutarem de todos os atrativos que a orla dispõe ou mesmo os impelem à marginalização em um lugar prioritariamente público; além disso, este estudo possibilita uma compreensão de fatores que provocam o deslocamento dos sujeitos residentes em localidades distantes, em direção aos espaços que podem ser utilizados sem cobrança.

É, portanto, função da pesquisa trazer à tona aspectos que auxiliem no desvelamento da relação entre os grupos e os espaços estudados, enquanto uma integração de recíproca mudança, pois cada grupo parece moldar o seu espaço de acordo com seus gostos, opiniões e status social.

\section{BREVE CONCEITUAÇÃO TEÓRICA}

\section{Tribo: marca cultural e meio de socialização}

Toda cultura ${ }^{9}$ é marcada pelo tempo e espaço presentes. As formas de vida apresentadas no decorrer das evoluções civilizatórias tornam frequentes o aparecimento de grupos de pessoas que se adéquam às modificações decorrentes da modernidade que se impõe. As mudanças exprimem outras exigências para a realidade atual, novas adaptações também em termos sócio-culturais.

Crianças, jovens e adultos possuem modos específicos de se ajustarem/interagirem ao meio e uma delas é mediada pelos grupos sociais dos quais participam, isso pode moldar o convívio, gostos, comportamentos e os demais modos de

\footnotetext{
9 De acordo com Chauí (2006, p. 250-251) o termo cultura é plural, pois os sistemas de proibição e permissão (leis), as instituições sociais, religiosas, políticas, os valores, as crenças, os comportamentos variam de formação social para formação social e podem variar numa mesma sociedade no decorrer do tempo.
} 
socialização. A existência de grupos sociais que possuem as características de tribo, é a marca de que há uma diferenciação nas formas de socialização ${ }^{10}$.

Para Costa; Pires (2006), cada grupo social dispõe de aspectos pessoais que se identificam por meio dos usos e costumes. Os autores destacam o modo de vestir-se apresentado, e esclarecem que as roupas desempenham um papel fundamental no que diz respeito à identificação e reconhecimento no grupo. Neste caso, a roupa transmite um significado por meio de uma linguagem que assegura a cada indivíduo o pertencimento a um determinado grupo social:

Esta linguagem se faz presente em várias circunstâncias, como na rua, no trabalho, na escola, na festa, as pessoas comunicam sua idade, seu sexo, seu nível social, sua personalidade, origem, gostos, enfim, uma série de informações que podem ser identificadas pela moda/indumentária (COSTA; PIRES 2006, s/p).

Percebe-se, portanto, que há uma interpretação dos modos de ser e conviver dos integrantes de um grupo, traduzida e reproduzida a partir da linguagem transmitida no modo de vestir dos indivíduos. Ela pode transferir um sentido de divisão de grupos, seja por sexo, etnia, nível social, faixa etária, prática esportiva e outros. Assim, a indumentária poderá configurar também, desafios de formas de poder, no sentido de status social; uma forma de estabelecimento de dominação/ocupação em torno dos locais frequentados; além de modelos culturais que correspondem às exigências ditadas pela sociedade.

Os meios sociais, os mais distintos espaços de encontros entre as pessoas, sejam físicos ou virtuais, são estimulantes do crescente surgimento de diferentes grupos, o que

\footnotetext{
${ }^{10}$ Lembrando que para o presente trabalho o termo tribo está baseado na conceituação trazida por Machado Pais em sua obra Tribos Urbanas: produções artísticas e identidades (2004), já definido no texto.
} 
possivelmente reflete a necessidade que as pessoas têm de não estarem sós, isto é, uma necessidade de criar vínculos a partir dos próprios modos de ser e viver.

Segundo Hack; Pires (2005), os agrupamentos entre os indivíduos constituem formas de socialização nas quais, principalmente a juventude, encontra referências e liberdade para organizar para si um modelo ideal de comportamento e vai formando sua identidade a partir das situações vivenciadas, considerando suas experiências, percepções e atuações no grupo.

As representações simbólicas ${ }^{11}$ e situações sociais provocam importante influência na sociedade hodierna refletindo nas ações, costumes e comportamentos dos grupos e das pessoas em particular. Por isso, pode-se dizer que o agir coletivo torna-se não somente uma referência para um membro, mas um modo permanente de adequação e formação de modelo ideológico de convivência entre os jovens.

Os estudos de Hack; Pires (2005) acerca das culturas juvenis apontam a criação de novos modos de vida como uma necessidade das novas gerações, as quais não podem ser entendidas puramente pelos conceitos geracionais e classistas $^{12}$, mas como organizações capazes de engendrar seus próprios anseios no cotidiano, consolidar sua representatividade social no tempo e no espaço presentes, ações que podem ser ou não contrárias às normas vigentes.

Neste ponto, enfatizamos que nos estudos de Pais (2004) ele aponta para as possíveis formas de comportamento das tribos, sendo a primeira uma forma submissa e a favor das normas vigentes, afim de não serem taxadas e assim, tornarem-se ao

\footnotetext{
${ }^{11} \mathrm{O}$ que de modo imperceptível age sobre os indivíduos, os quais consciente ou inconscientemente se fazem cúmplices de sua existência e de seu poder provenientes de estruturas sociais que transmitem ideais de uma cultura dominante (BOURDIEU, 2007).

${ }^{12}$ Para os autores o conceito geracional de juventude provém de definições funcionalistas do processo de socialização o qual deve ocorrer continuamente através da conservação ou sedimentação das relações entre as gerações. Já a conceituação classista é determinada através da representação social do jovem (sexo, etnia e principalmente classe social).
} 
máximo aceitáveis nos meios sociais, ou ao menos imperceptíveis. Em contrapartida, a segunda não mede esforços para subverter a ordem do seu campo, do seu espaço, com o objetivo de ser percebida, mesmo que esteja à margem.

Estas formas de adequação à sociedade são diariamente enfrentadas pelos jovens que buscam o reconhecimento social, que criam a cultura do seu tempo, procuram raiz identitária e moldam seu modo de ser no mundo.

É válido ressaltar que as inferências da sociedade não estão restritas à juventude, elas englobam de certa forma indivíduos de todas as idades, sexo e etnias. Por isso, as tribos ou agrupamentos sociais destacados na presente pesquisa também podem criar e recriar seu próprio contexto, desenvolver suas potencialidades e subverter as normas impostas pelo sistema no tocante aos modos de vida, gostos, usos e costumes, enfim, ao seu universo cultural de acordo com interesses que não priorizem aspectos econômicos e consumistas e sim, circunstâncias que possam contribuir no "avanço individual ou coletivo do processo de desenvolvimento do homem" (PIRES, 2002, p. 130).

\section{Compreensão acerca do lazer}

Um acontecimento característico dos grandes centros urbanos é o aglomerado de pessoas que buscam em um local específico, objetivos em comum. Nas tribos, as pessoas encontram modos de explorar juntas, principalmente espaços de entretenimento e de lazer, com destaque os jovens.

As pessoas encontram-se normalmente em busca de preencher os horários de não trabalho, destinando-os a algum tipo de diversão ou distração, o que hoje denominamos de lazer. Esse tempo à parte, do pouco que resta dentre o tempo destinado aos muitos afazeres de dias de intenso trabalho na sociedade do "ontem", da pressa, do 
tempo medido milimetricamente para dominar o próprio deus da cronologia. Tempo valorizado, organizado e direcionado a atividades que nem sempre correspondem ao verdadeiro objetivo imaginado pelas próprias pessoas.

Sendo recente, o termo lazer é característico da sociedade pós-revolução industrial. Dumazedier (1974), pesquisador deste termo, explica que na sociedade grega os homens consideravam de suma importância para os cidadãos, uma vida de contemplação da natureza, de reflexão, logo, a necessidade do ócio. Ele percebeu o ócio como um momento de dedicação às meditações, que normalmente se dava em locais abertos, próximos aos mais naturais elementos.

No entanto, este autor não considera que os termos contenham o mesmo significado, habitualmente lazer e ócio são entendidos normalmente como sinônimos, porém, as suas significações exprimem épocas bastante distintas da história da humanidade. Entende-se que sempre existiu o tempo do não trabalho, no entanto, ociosidade denota o estilo de vida dos fidalgos gregos, paga pelo trabalho dos escravos. Por outro lado, isso não exprime a existência do lazer, visto que este segundo termo detém características específicas da civilização moderna ou pós-industrial.

A ociosidade dos nobres estava sempre ligada aos mais altos valores da civilização, mesmo quando na realidade ela era marcada pela mediocridade ou pela baixeza. Entretanto, o conceito de lazer não convém para designar as atividades destas castas ociosas. O lazer não é ociosidade, não suprime o trabalho; o pressupõe. Corresponde a uma liberação periódica do trabalho no fim do dia, da semana, do ano ou da vida de trabalho (DUMAZEDIER, 1974, p. 28).

O tempo livre que as tribos observadas preenchem com jogos de recreação, passeios, atividades físicas e de relaxamento, teria sob o prisma sociológico, duas vertentes para possíveis análises considerando uma visão maniqueísta. Por um ângulo, os estudos sobre o ócio apontam os elementos primordiais a esta atividade, que 
resumidamente ficam caracterizados como oportunidade do desenvolvimento intelectual humano e progresso da cultura. Por outro ângulo, o controverso lazer é considerado mais uma criação forçada da sociedade capitalista, marcado pelas características da cultura consumista de massa (DUMAZEDIER, 1974). Desse modo, o lazer ao qual se destinam os espaços construídos no complexo da Orla de Atalaia pode ser representado pelos interesses que movem as tribos a aproximarem-se destes locais.

Travada a discussão do que seria o lazer mais recentemente, Nelson Carvalho Marcellino esclarece que o entendimento deste na atualidade é bem distinto do entendimento de ócio da Antiguidade Clássica, mas se resume ao significado dado por Dumazedier. Portanto, de acordo com Marcellino (2007), o entendimento do lazer não é estabelecido em si mesmo, ele constitui a cultura e por isso, é um elemento historicamente situado. Assim,

\begin{abstract}
A especificidade concreta do lazer, considerado em sua manifestação na sociedade atual, é colocada como reivindicação social. [...] é uma questão de cidadania, de participação social. [...] é visto com fruto da sociedade urbano-industrial e, dialeticamente, incide sobre ela como gerador de novos valores que a contestam. [...] é entendido como especificidade concreta e, na sua especificidade, com possibilidades de gerar valores que ampliem o universo da manifestação do brinquedo, do jogo, da festa, da re-creação, para além do próprio lazer. (MARCELLINO, 2007, p. 12-3)
\end{abstract}

Em suas mais variadas facetas de mantenedor ou subversivo, o lazer é a dedicação a esse tempo do não trabalho, é também representado como meio de produção cultural, de livre expressão das pessoas que vão à busca de aproximar-se de si mesmas, nos espaços nos quais se encontram com seus afins; como formação dos grupos sociais que podem dar continuidade à forma manipulativa das relações de poder do mundo profissional; e em último aspecto, um motor de movimentação de capital nos espaços onde necessariamente é exigido investimento em troca da utilização, ou seja, o caráter 
estimulante e prazeroso do entretenimento transforma este serviço em moeda de troca, uma mercadoria não material.

\section{PROCEDIMENTOS METODOLÓGICOS DA PESQUISA}

A construção deste estudo configurou-se como uma pesquisa qualitativa, de natureza descritiva a partir da realidade observada e analisada, a fim de proporcionar o conhecimento sobre o objeto de estudo mediante a possibilidade de correlacionar o fenômeno e as possíveis variáveis (MINAYO, 2007; TRIVIÑOS, 2006).

Os grupos sociais aos quais nos direcionamos no presente estudo, encontram-se não somente vinculados aos propósitos inerentes da pesquisa, bem como ao contexto formado pelas inúmeras diversificações culturais, econômicas, políticas e sociais existentes. Fatores que exercem influência sobre toda a comunidade que se aglomera em busca dos espaços de lazer do Complexo Orla.

Diante disso, pode-se dizer que a seleção dos grupos aqui apresentados se deu a partir da primeira aproximação dos pesquisadores com os pesquisados, bem como pela ligação com as práticas corporais esportivas e de lazer dos sujeitos investigados.

Para Triviños (2006) as formas de vida precisam, além de tudo, serem interpretadas, não basta descrevê-las, é preciso conduzi-las a um entendimento mais amplo. Sendo assim, para melhor interpretação e análise das relações entre as tribos e os espaços de lazer da orla, foi construído um vídeo-texto a partir de filmagens e fotografias que também serviram de suporte para as análises dos acontecimentos juntamente com as anotações diárias construídas ao longo das observações in locus, pois se trata de formas de vida, de linguagens e diferenças sócio-culturais, que necessitam de uma observação atenta. 
Desse modo, os grupos se tornam protagonistas da vida real e fonte de análise dos olhares atentos dos observadores. De acordo com Ribeiro et al (2003), essa construção possibilita o rememorar dos fatos através dos meios tecnológicos, não como deslumbramento, mas como aproximação das "pessoas vivas" com as imagens da realidade e contribui para o entendimento acerca das questões de ocupação desses espaços.

Destacamos, portanto, a câmera fotográfica e filmadora como recursos técnicos para registrar a partir de uma sequência de imagens, os espaços muitas vezes marcados pelas gravuras, desenhos e símbolos, como parte da identidade do grupo. Eles também trouxeram informações a respeito dos sujeitos, o que possibilitou o desenvolvimento do processo de entrevista com um modelo semi-estruturado, utilizado como instrumento de coleta de dados. Contando ao todo com cinco entrevistas realizados em grupo com os sujeitos encontrados e uma entrevista com um representante de uma instituição descrita nas análises, totalizando seis entrevistas.

O desenvolvimento do Diário de Campo (DC) com anotações de dados como datas e horários de visita à Orla de Atalaia, merece destaque visto a sua importância na identificação de espaços que pudessem transmitir as imagens necessárias à captação informações. Assim, os locais de filmagens foram representados pelas pistas de skate, de patinação, de caminhada, de ciclismo, de kart; pelas quadras poliesportivas, de basquete, de vôlei; pelos lagos, fontes luminosas e monumentos, entre outros.

Contudo, foi mediante a captação das imagens ${ }^{13}$ na Orla de Atalaia de uma

\footnotetext{
${ }^{13}$ As imagens foram um ponto de apoio tanto para identificação como para interpretação dos dados da pesquisa. Usando timidamente o modelo baseado em Goellner et al (2010) quando trata de estudos culturais, nos quais as imagens são práticas sociais linguisticamente construídas [...], pois além conter signos, símbolos e significados, criam sentidos, expressam relações de poder e enunciam posições de sujeito (GOELLNER et al, 2010, p.19).
} 
forma mais abrangente em sua extensão - ponto de observação - que identificamos os sujeitos como aqueles que se dirigem até o complexo, mantêm uma frequência e desfrutam do seu espaço para alguma prática corporal esportiva ou de lazer.

Estrategicamente as aproximações se deram a partir de visitas regulares ao cenário observado, o qual foi fotografado e filmado em horários distintos na intenção de demonstrar suas características em: estrutura, que consiste em monumentos, pistas, quadras, lagoas, bares, hotéis; extensão, equivalente a seis mil metros de extensão; e atrativos, shows, campeonatos, exposições.

Os dados da pesquisa foram coletados durante um período de um ano e um mês, entre os meses de dezembro de 2008 e janeiro de 2009. Nos três primeiros meses as visitas foram mais intensas chegando a três vezes por semana em virtude do início do projeto ao qual está vinculada (Projeto Orla) e que estaria também em andamento. Em princípio, as visitas eram irregulares em dias diferentes da semana, desde a segundafeira até o domingo. Conforme a identificação dos grupos que poderiam ser observados, passamos a fazer as visitas somente nos dias horários de maior aglomeração, ou seja, nos finais de semana nos turnos vespertino e noturno.

Nos meses que se seguiram buscamos nos aproximar das pessoas, dos grupos, sempre marcando presença com os equipamentos de observação, pedindo licença para fotografar, filmar, conversar, chegando até a participar de um treino com a tribo do hóquei. Assim, em mais três meses definimos as tribos que fariam parte da pesquisa, e nos demais (com duas visitas/mês devido ao pouco tempo disponível dos pesquisadores para o deslocamento até o complexo de lazer) foram realizadas as entrevistas de acordo com a disponibilidade dos grupos. 


\section{Descrição do local da pesquisa}

No período de um ano, ao passo que fomos identificando a frequência no mínimo de utilização semanal das tribos, foram realizadas em igual tempo as entrevistas e filmagens que deram embasamento à descrição dos locais.

O complexo de lazer Orla de Atalaia possui uma infra-estrutura por ora acessível e em boas condições, portanto, as chances de encontrar pessoas utilizando seus espaços também eram positivas. Os locais específicos nos quais encontramos as tribos são diferenciados desde manutenção à localização ou trecho do complexo, levando em consideração os seis quilômetros de extensão, conforme podemos melhor visualizar na (FIG. 1).

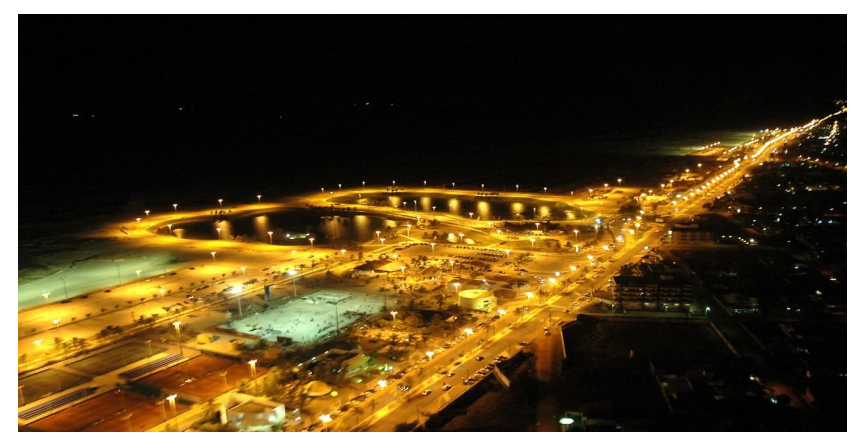

FIGURA 1: Visão aérea noturna da Orla de Atalaia Fonte: www.skyscrapercity.com. Fotógrafo: Jorge Henrique

Descrevendo o primeiro espaço, podemos apresentá-lo como o Cara de Sapo Skatepark (conforme FIG. 2), um Complexo de Esportes Radicais que até 2008 era o único no Brasil que possuía todas as especificações técnicas para a realização de competições de nível internacional, contando com uma dimensão de quatro mil metros quadrados, pista para prática vertical (Half Pipe) e vários obstáculos para o Street (banks, funbox, wall ride, quartier pipe, escadas, pirâmides com escadas, caixote e savana com corrimão), sendo ao todo 27 obstáculos $^{14}$. A pista de skate maior de Aracaju

\footnotetext{
14 Dados encontrados no endereço eletrônico: http://www.skatistaonline.com/category/cidade/aracaju, acesso em 30 de março de 2011.
} 
e segunda maior do Brasil ${ }^{15}$ tem uma característica única em relação aos demais locais observados, desenhos de grafitagem e pichação entre nomes e símbolos adornam o lugar.

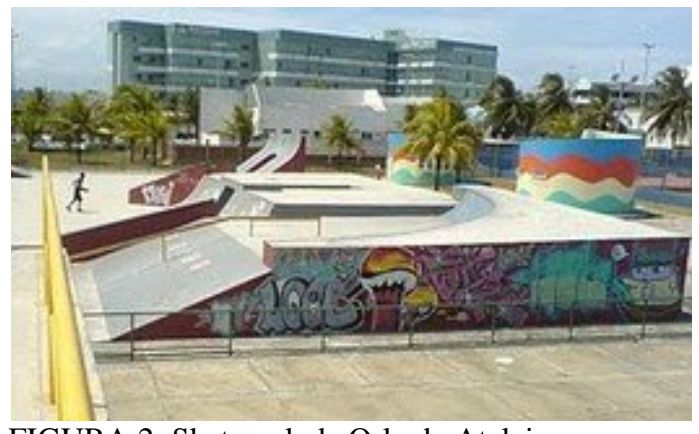

FIGURA 2: Skatepark da Orla de Atalaia

Fonte: http://www.skateparksdobrasil.com/2011/01/ cara-de-sapo-skatepark-aracaju.html

Por ordem, o Kartódromo Emerson Fittipaldi é o segundo espaço descrito, como podemos ver na (FIG.3). Inaugurado no ano de 2005, fica localizado na segunda etapa da Orla de Atalaia, com estrutura em adequado estado de conservação e espaço para 2500 pessoas na arquibancada, ainda não possui infra-estrutura para grandes eventos, mesmo assim realiza campeonatos de kart anualmente, porém sem intensa divulgação. Este espaço, da orla está sob a responsabilidade da Federação Sergipana de $\operatorname{Kart}^{16}$, a qual em sua administração utiliza o espaço com fins lucrativos, fator que nos chamou atenção, pois até então não podíamos entender até onde se limitava à característica do espaço que é público tornar-se propriedade privada.

15 Informação encontrada no site: http://www.doztribos.com.br/noticia/skate-sergipano-possuivisibilidade-junto-cbsk, acesso em março de 2011.

${ }^{16}$ De acordo com Paulo Silveira, presidente da Federação Sergipana de Kart, a instituição funcionava no centro da cidade, as corridas eram realizadas na Praça Marechal Deodoro, mas acidentalmente um piloto atingiu um espectador, motivo pelo qual os corredores paralisaram suas atividades, retornando somente cinco anos depois na Avenida Maranhão, Siqueira Campos, bairro periférico da capital. Utilizava um espaço cedido pelo Aeroclube, porém existiam desde essa época e já realizavam corridas na orla, talvez estímulo para o Estado de Sergipe incluir o kartódromo no projeto de construção da Orla. 


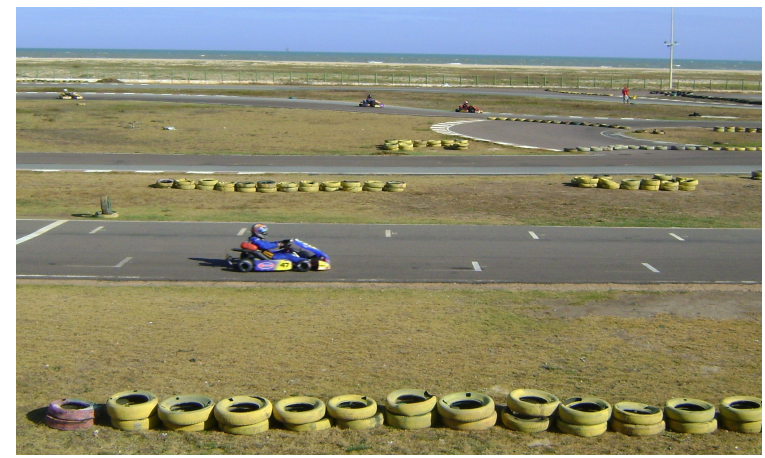

FIGURA 3: Kartódromo Emerson Fittipaldi

Fonte: fotografia do período de observação da pesquisa. Por: Luciana Pina Garcia e Paula Aragão

O terceiro espaço é a quadra de futsal (FIG. 4), utilizadas pelos "boleiros do final de semana", a tribo dos jogadores de futsal. É um espaço conservado e adequado com dimensões padronizadas da prática esportiva específica, fica localizado no final da primeira etapa da orla, mais acessível ao transporte coletivo.

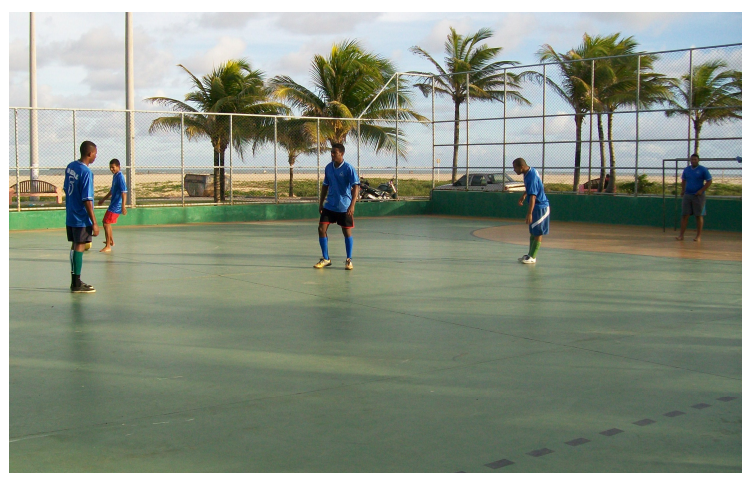

FIGURA 4: Quadra de futsal da Orla de Atalaia

Fonte: fotografia do período de observação da pesquisa Por: Luciana Pina Garcia e Paula Aragão

Por fim, a quadra de handebol finaliza a lista de espaços descritos. Em níveis adequados de condição de uso, fica ao lado da quadra de futsal e curiosamente abriga o treino da tribo mais inusitada encontrada no espaço da orla, a tribo dos jogadores de Hóquei sobre patins. Enfim, quadras e pistas abrigam ao todo seis tribos apontadas na pesquisa, as quais após suas descrições fomentam questionamentos antes não 
mencionados, mas que ainda assim seria impossível realizar as seguintes análises sem considerá-los.

\section{Descrição das Tribos}

É certo que a extensão da Orla de Atalaia proporciona uma aproximação com um grande contingente de pessoas, díspares em intenções, mas semelhantes na ocupação de um espaço de tempo encontrado em seu ritmo diário frenético, o preenchimento de um tempo diferente do qual é destinado a sua ocupação empregatícia.

Dentre tantas pessoas que frequentam o complexo para os mais diversos fins, desde o lazer à prática esportiva, da contemplação dos recursos (naturais e artificiais) do espaço à forma de adquirir recursos para o próprio sustento, focamos a pesquisa exatamente em grupos que estavam frequentando a Orla durante o período de observação. De acordo com o DC, quatro grupos atraíram a atenção pelo fato de ocuparem espaços localizados em etapas distintas do complexo ${ }^{17}$.

Em torno de dez tribos foram encontradas a partir das observações, porém por motivo de ausência de maior número de pesquisadores delimitamos o campo para aquelas que frequentavam os espaços nas três etapas da orla e que realizassem práticas corporais esportivas ou de lazer. Outros fatores foram o horário e os dias encontrados para realizar a abordagem in loco, sendo ambos escolhidos por aqueles de maior aglomeração e tempo de permanência no local e, portanto, a sexta-feira, o sábado e o domingo predominaram para as observações dos campos e realização das entrevistas.

Sendo assim, seis tribos foram escolhidas, considerando que três delas ocupavam o mesmo espaço. Os skatistas constituem a primeira tribo da Orla, o grupo

\footnotetext{
${ }^{17}$ Durante as observações para melhor acompanhamento dividimos o complexo em três etapas, em virtude da sua longa extensão.
} 
que ocupa o Cara de Sapo Skatepark. Um aglomerado que se divide entre si, formando pequenos grupos, mas que de um modo geral tem um gosto em comum, a prática do skate. Nem sempre dispostos a conversar nos delimitamos a entrevistar aqueles que se mostraram mais permissivos, além de filmar as várias manobras com técnicas perfeitas e também os tombos dos mais ousados e dos aprendizes. Meninos e meninas comungando do mesmo espaço, sem grupos femininos ou masculinos, mas tribos mistas com idade média entre doze e vinte e cinco anos.

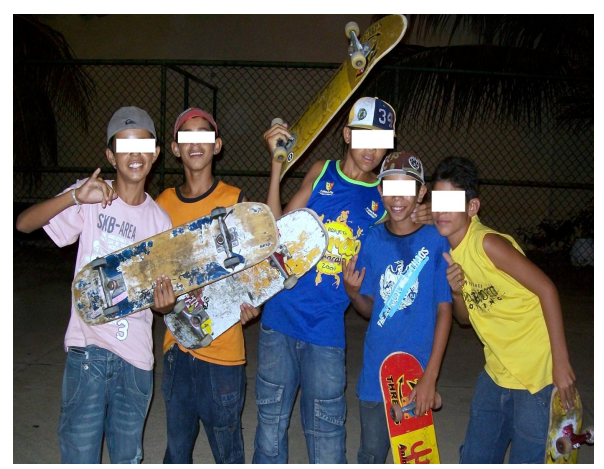

Foto 05: Integrantes da "Tribo do Skate" Fonte: fotografia do período de observação da pesquisa, por Luciana Pina Garcia e Paula Aragão

Os patinadores ocupam este mesmo espaço, o Skate Park, ora de modo amigável, ora conflituoso como veremos nas análises. Ainda que em menor número, eles se destacam entre os skatistas pelo desempenho, velocidade e uso de vários equipamentos, desde os mais habilidosos aos iniciantes. Esta foi uma tribo observada, porém, nenhum relato de entrevista foi feito, pois os patinadores se mostraram indispostos a conceder entrevistas, mas um fator interessante é que assim como os skatistas, meninos e meninas faziam parte da mesma tribo.

Já a terceira tribo que também ocupava este mesmo espaço foi denominada de "bicicleteiros", termo usado para diferenciar dos ciclistas profissionais e definir aqueles que apenas estavam se divertindo, brincando, ainda que também tivessem a intenção de 
ser um esportista profissional futuramente. Com idade média entre doze e quatorze anos (homens), a maioria deles andava sem equipamento, às vezes nem mesmo uma sandália para proteger-se dos tombos, freadas bruscas ou dos estilhaços de vidro por vezes encontrados no chão da pista.

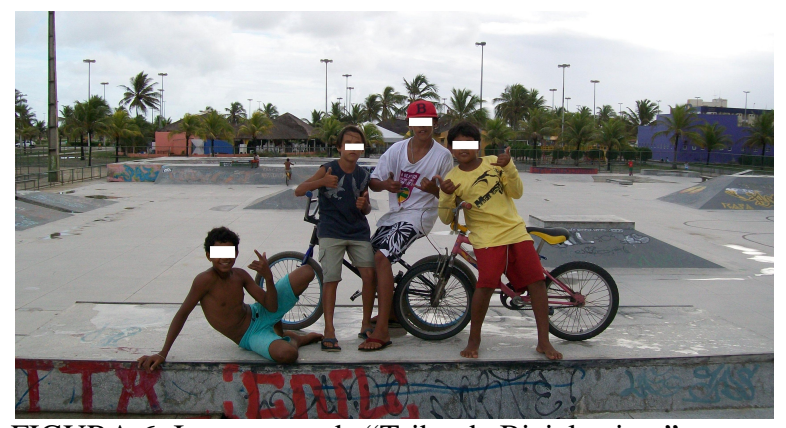

FIGURA 6: Integrantes da "Tribo de Bicicleteiros"

Fonte: fotografia do período de observação da pesquisa Por: Luciana Pina Garcia e Paula Aragão

Em outro espaço encontramos os pilotos de kart. O Kartódromo Emerson

Fittipaldi abriga uma tribo constituída por um grupo de empresários e amigos que mantêm viva a Federação Sergipana de Kart. Percebemos que há uma relação familiar nesta tribo, pais e filhos correm juntos (homens), são adeptos das corridas de kart e por isso há uma grande variação na idade, que vai desde os dez aos quarenta anos. Bem equipados, os pilotos mostram-se conhecedores peritos da prática e compromissados com os treinos ou momentos de diversão.

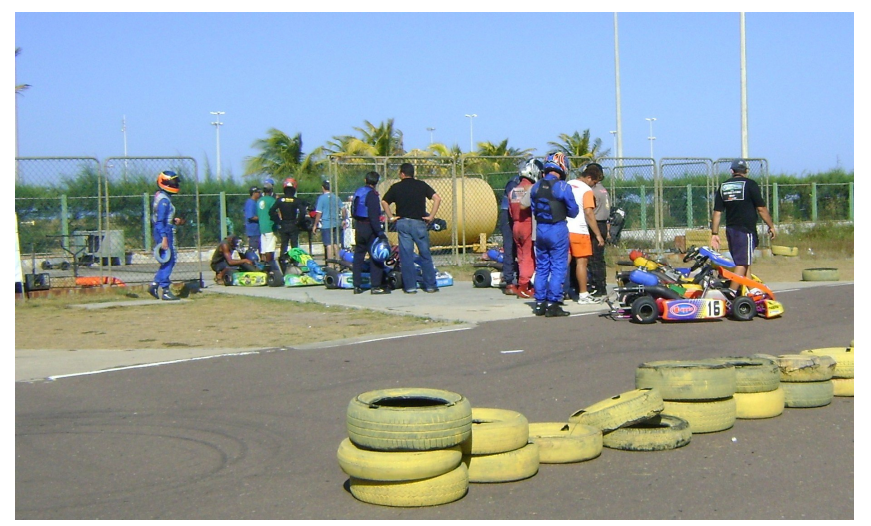

FIGURA 7: Integrantes da "Tribo do Kart"

Fonte: fotografia do período de observação da pesquisa Por: Luciana Pina Garcia e Paula Aragão 
$\mathrm{Na}$ primeira etapa da Orla encontramos os jogadores de futsal de final de semana, uma tribo constituída por trabalhadores (homens) de uma mesma empresa com idade média entre vinte e trinta e cinco anos. O fato de serem da mesma empresa não é coincidência, o que faz esta tribo ter um diferencial das demais, o fomento dos seus empregadores à prática do esporte escolhido, fornecendo fardamento e promovendo campeonatos entre os pólos da rede da empresa com premiações.

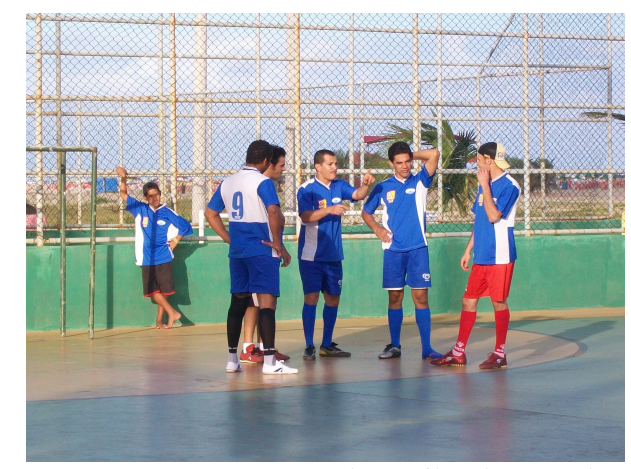

FIGURA 8: Integrantes da "Tribo do Futsal"

Fonte: fotografia do período de observação da pesquisa, por: Luciana Pina Garcia e Paula Aragão

E a última das tribos da pesquisa também apresenta um diferencial, porém este é da própria prática escolhida, o hóquei sobre patins. Um grupo único em Aracaju que homenageia um time que já existiu, o Bravs, dizendo ser renascido das cinzas por isso o nome de Fênix. Com este nome, o grupo se consagra como o único da capital, quiçá do estado de Sergipe e realiza seus treinos semanais na quadra de handebol próxima à de futsal na primeira etapa do complexo. O grupo mantém uma freqüência assídua de treino aos finais de semana e possui equipamentos adequados à prática apesar do custo financeiro para cada membro. São jovens, homens, entre vinte e vinte e dois anos, universitários que treinam com a responsabilidade de um time que almeja o profissionalismo e que se diverte ao mesmo tempo. 


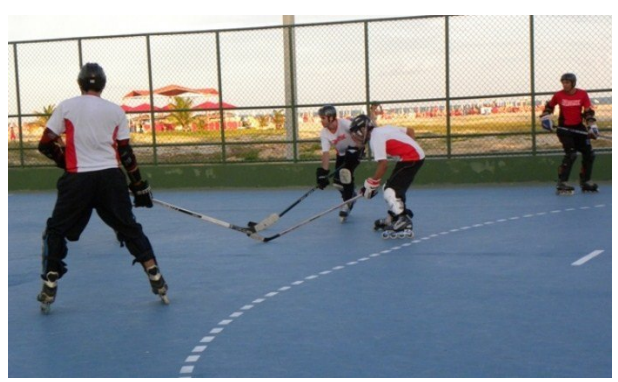

FIGURA 9: Integrantes da "Tribo do Hóquei"

Fonte: fotografia do período de observação da Pesquisa, por: Luciana Pina Garcia e Paula Aragão

\section{APROXIMAÇÃO DAS ANÁLISES}

Para iniciarmos a análise da pesquisa, apresentamos os sujeitos que contribuíram para o desenvolvimento das observações e do nosso quadro de filmagens, fotografias e entrevistas: os "habilidosos" skatistas (SK) e os patinadores (PA), os bicicleteiros (BC) "sonhadores" (como futuros profissionais da Bike Cross), os jogadores de futsal "de final de semana" (FS), os "pilotos" do kart (KA), os "quase desconhecidos" jogadores de hóquei (HO).

Durante as observações, dois espaços de lazer da Orla, administrados pelo $\mathrm{SESC}^{18}$, dos quais alguma tribo poderia estar usufruindo, curiosamente nunca foram vistos sendo ocupados. Assim, com a oportunidade, pudemos entrevistar o diretor local, com interesse em seus relatos fizemos exceção, pois não se trata de tribo, mas de uma obstrução de uso de um equipamento de lazer, por isso incluímos nas análises alguns trechos da sua entrevista, identificados por administrador do SESC (AS).

Além das indagações norteadoras desta pesquisa, outros aspectos relevantes foram surgindo ao longo da aproximação do campo de estudos mediante os recursos

\footnotetext{
${ }^{18}$ Serviço Social do Comércio em Aracaju-SE, grupo que visa garantir a excelência na prestação de serviços, contribuindo para a qualidade de vida dos trabalhadores do comércio de bens e serviços e comunidade em geral, através dos programas: Educação, Saúde, Lazer, Cultura e Assistência.
} 
utilizados. A partir de então, surgiram algumas temáticas que contribuíram para as análises das entrevistas, fruto do próprio campo investigativo.

Delimitaremos no primeiro momento das análises duas fases da observação. Faremos um diálogo entre trechos das entrevistas, análises das filmagens e imagens do arcabouço de dados e a concepção teórica, exercício do qual resultará a identificação ou primeira fase, relativa ao estado à aproximação com a prática esportiva ou de lazer, o porquê da escolha. A segunda fase, de identidade, refere-se ao processo de socialização que se cria entre os pares dentro das próprias tribos, o sentimento de pertença, as peculiaridades do grupo e do equipamento ocupado e o encontro com práticas inusitadas, pouco conhecidas na cidade.

Dando continuidade às análises, concentramos atenção em temáticas suscitadas a partir dos estudos das entrevistas. Pela recorrência dos fatos consideramos relevante tratar das questões de acessibilidade, da qualidade dos equipamentos e das incógnitas público/privado, pois todas giram em torno do modo pelo qual a(s) tribo(s) se apropria(m) do(s) espaço(s) ou como ela(s) é (são) $\operatorname{sustada(s)~do(s)~} \operatorname{seu}(\mathrm{s})$ equipamento(s). Isso, claro, sem esquecermo-nos da relação oportuna na realização da prática de lazer e o jogo mercadológico que nos faz questionar a atuação governamental com as políticas públicas.

\section{Do relacionamento entre as pessoas às práticas esportivas não convencionais}

Dentre os motivos que impelem os grupos a se agradarem das práticas de lazer que a Orla oferece, encontramos também razões para algumas pessoas se encontrarem e se descobrirem em gostos e estilos, demonstrando o caráter do tempo livre de incentivo à criação, expressão e satisfação de um grupo, ou de um membro do grupo, 
considerando neste aspecto, o sentimento de pertença em relação a alguma tribo como demonstração da função de socialização desses grupos apontada por Hack; Pires (2005).

[...] quando eles começaram a fazer a pista eu vinha passear na orla e também eu via a galera andando, me interessei pelo skate, $[\ldots]$ to andando até hoje. [...]. A pista sem dúvida é mais fácil pra mim, mais prático, que na verdade foi aqui que comecei a andar de skate, [...] Então, já tem, vamos dizer, um afeto maior [...] Conheci todos a partir do momento que comecei a andar de skate (SK).

[...] O primeiro encontro de amigos pra jogar hóquei foi no Cordesi (colégio) e logo após no Arqui (colégio Arquidiocesano) [...] (HO)

A partir do primeiro encontro, a tribo do hóquei sobre patins buscou locais mais adequados para treinar, e juntos os membros encontraram a quadra de handebol, que para eles tem proporções e piso mais adequados em relação aos anteriores. Assim, se organizaram com os equipamentos e mantêm o hábito de treino semanal na orla.

Existe uma grande diversidade que marca o grupo, mas que em pequenos aspectos chama atenção e se torna algo que o identifica. Ao verificar os relatos da skatista destacamos outro aspecto relevante para a formação das tribos, suas peculiaridades. Costa; Pires (2006) enfatizam em seus estudos a importância da identidade de uma tribo, das principais características que consolidam sua existência, principalmente quando se trata da indumentária, sem negar as individualidades.

Destacamos as seguintes afirmativas acerca dos skatistas.

Assim, você pode reparar que talvez não, as pessoas que estão assim de fora quando olha podem perceber todo mundo igual, mas quem freqüenta aqui, anda de skate mesmo, que tem primo parente, enfim, percebe que não é bem assim. Cada um tem um estilo de roupa diferente, cada um tem uma maneira de andar de skate diferente né? Um anda com mais impacto, outro anda com manobras mais técnicas e assim vai [...] algumas pessoas preferem andar com uma calça mais larga, porque tem mais facilidade de movimento, outras pessoas já preferem mais justas, porque a calça pode enrolar, pode embolar na roda, pode atrapalhar na hora que tiver mandando a manobra. Então, isso é de cada pessoa mesmo. (SK) 
[...] Porque a roupa de skatista tem gente que usa mais as calças punk, que é apertadinha aqui (na perna), tem outras mais folgadas, o tênis que é diferente também. (SK)

Já em relação à caracterização do equipamento de lazer, não há muita concordância para combinação entre as marcas existentes no Skatepark e os seus usuários. Isso fica claro em falas de participante da mesma tribo:

Eu acho que sim. Têm muitos que gostam [...] Tem algumas coisas que eu acho legal assim, mas não é meu estilo, assim, grafite. (SK)

Acho legal. É porque é a arte dos grafiteiros e também deixa a pista mais aquele estilo skatista. (SK)

Eu acredito que toda forma de arte, porque os grafites e até mesmo as pichações não deixam de ser uma forma, e todas essas formas de arte tem um significado diferente para cada pessoa. [...]. Mas eu acho que combina um pouco assim, com o skate em si, o jeito despojado, as letras mesmo podem significar alguma coisa pra mim, mas pra você não é a mesma coisa, não pode significar nada [...]. Sim, sim. Eu acho que é um ponto que a gente pode tirar o estilo mesmo, eu acho que dá pra você encaixar o skate dentro dessa forma de arte. Desse tipo de arte (SK).

Em se tratando de caracterização do local com marcas peculiares, aparentemente feitas pelas tribos usuárias, as atenções se voltaram para a pista de skate, pois somente ela apresentou marcas, que ora aparecem, ora desaparecem ao longo das reformas e dos gostos dos pichadores. Nos demais espaços apenas propagandas de patrocinadores no caso do kartódromo e a identificação em placas do Governo do Estado nas quadras.

Em alguns trechos das entrevistas com as demais tribos também é possível detectar o prazer de estar vivenciando os momentos de ociosidade com a prática escolhida, como por exemplo: 
[...] quando eles começaram a fazer a pista eu vinha passear na orla e também eu via a galera andando, me interessei pelo skate, achei uma prática legal e pedi um skate a meu pai e minha mãe. Acharam meio estranho assim, no momento, mas me deram e to andando até hoje. (SK)

[...] Tenho 12 anos, gosto de vim aqui todos os dias porque eu sou muito "securento". (BC)

E o ambiente amigável e de aceitação entre os pares:

Eu tenho muitos amigos aqui, sabe, todo mundo aqui é muito amigo e eu gosto pra caramba de andar de skate. Não sei dizer muito bem, mas é uma inspiração que a galera sabe andar bem aqui aí eu me inspiro nessas pessoas. (SK)

Neste contexto, observamos que existem modalidades esportivas até então despercebidas pela comunidade aracajuana, é o caso do Hóquei. Além da dificuldade de aceitação da modalidade, os praticantes têm que driblar todas as dificuldades para consolidar esta prática esportiva. Os jogadores de hóquei relatam toda a dificuldade de comprar um equipamento muito dispendioso:

Aqui se você for ver só o preço dos patins é um absurdo! É quem pergunta isso (custo para entrar no time), falo logo, olha não é barato não. A gente não compra equipamento todo novo, porque já compra usado mesmo, mas procura saber se tá num estado bom e tal! (HO)

Mas também expressam o ganho de todo o esforço:

Nada fora o prazer do próprio esporte! (HO)

Financeiramente, nada! Mas em questão pessoal... Satisfação! (HO)

Os depoimentos acima apontam a evidente ausência de uma política pública de incentivo a práticas esportivas e de lazer pouco difundidas. Tivemos a oportunidade de 
constatar que onde o time treina, sendo uma quadra destinada para o handebol, nunca encontramos um time de handebol jogando e usufruindo desse equipamento.

Como identificado na descrição e caracterização das tribos ao logo do processo de observação se trata da presença mínima de pessoas do gênero feminino. O público feminino é mínimo frente à oferta de opções de lazer do complexo e sua presença é tão inusitada quanto à dos jogadores do hóquei.

Mas como tratamos nesse item da relação entre as pessoas que compõem as tribos, fazemos essa ressalva para destacar a relação harmoniosa entre os meninos e meninas, constituindo um marco para as Tribos da Orla. Este marco, portanto, criou novos posicionamentos acerca dos estudos das tribos, primeiro em relação à convivência entre os gêneros na tribo (Skate); em segundo lugar questionamos a ínfima presença de um público feminino usuário dos equipamentos.

Para tanto, deve-se saber que as definições de gênero, para qualquer relação social, são construídas pela própria sociedade. Para Goellner et al (2009) gênero é uma condição social da qual identificamos o masculino e o feminino, não sendo, pois algo natural, mas construído social e culturalmente, neste sentido a falta da presença feminina pode ser vista como algo que perpassa o masculino e o feminino e os usos de espaços públicos de lazer para além de uma determinação social.

Sendo a sociedade uma determinante para as condições de afirmação social e espacial dos gêneros, podemos identificar, conforme depoimento de uma skatista, ao se referir sobre a opinião de seus pais em relação à sua opção pela prática do skate:

[...] achei uma prática legal e pedi um skate a meu pai e minha mãe. Acharam meio estranho [...], mas me deram [...]. (SK1) 
Pergunta-se o porquê do estranhamento dos pais em relação ao desejo da filha. Seria estranho a prática ou o gosto de uma menina pela prática do skate? Talvez convencionalmente a sociedade habituou-se a associar uma prática corporal a um estereótipo ou a gêneros (às mulheres, gestos leves, suaves, nada de força ou potência; aos homens, agilidade, força e potência).

Entre os membros da tribo dos skatistas, as meninas afirmam que não há problema com a presença delas no Skatepark e sempre aparecem interessadas, no entanto, há um desabafo quanto à valorização da prática em competições, exemplo:

[...] todo mundo anda normal aqui, somos amigos [...] Eu acho que o skate feminino ta crescendo aqui em Aracaju vai aos poucos, porque não tem muitas meninas que praticam, mas já tem uma dez no total (que praticam para nível de competição) e eu acho muito interessante, porque elas vêem a gente andando aqui e acham bonito ou então, sei lá, o estilo e aí começam a andar também. E falar também sobre competição, acho que aqui em Aracaju o skate feminino não é muito valorizado, aí a categoria que é a principal mesmo é o Amador I e o Open (categorias exclusivamente masculinas), [...] acho que eles deviam olhar também pra o lado do skate feminino porque, sei lá, a gente se sente muito no canto, discriminado um pouco, porque eles (patrocinadores e organizadores de eventos) não dão valor. (SK2)

Portanto, fica em relevo a proposta de adequação aos espaços de práticas corporais da Orla de Atalaia. Podemos classificar como uma responsabilidade administrativa que envolve discussões no âmbito das políticas públicas, pois é visível que $90 \%$ dos equipamentos específicos estão voltados para práticas esportivas convencionais, e curiosamente o espaço que não se destina a tal é justamente o que abriga um pequeno contingente, por isso, significativo de grupos mistos, com presença feminina com idade média de vinte anos.

É possível pensar que o complexo poderia ser contemplado com outros equipamentos que pudessem atrair a presença feminina - aqui defendemos a inclusão 
das mulheres como usuárias, não como meras observadoras de práticas corporais e esportivas "alheias" (masculinas). Podemos ainda questionar se para a construção do complexo o público alvo foi considerado relevante e ainda se dentro deste contingente houve uma intenção de atrair o público feminino ou a ideia ficou limitada ao fluxo turístico, independente de quem utilizaria cada espaço.

Todos estes relatos demonstram que as pessoas se identificam de acordo com seus gostos e estilos e, a partir de então, tornam-se parte de uma identidade social. As tribos são o exemplo de convivência, de usufruto de uma prática em comum sem preocupação ou compromisso com algo além daquele espaço, pois é um tempo de inspiração, criação e de aceitação do outro do jeito que ele quer ser ou quer se mostrar, independente do gênero em casos específicos como na Tribo do Skate.

Essa pesquisa proporciona um espaço para possíveis reflexões políticas ou de opinião pública. Este aspecto pode ser observado nos depoimentos referentes à predominância de equipamentos para práticas esportivas convencionais, direcionando o incentivo às práticas já conhecidas como basquetebol, futsal, voleibol e handebol, quando se percebe que se deixa de lado o fomento ao conhecimento de práticas diferentes ou não convencionais como o hóquei.

\section{Acessibilidade e qualidade das estruturas da Orla: uma questão pública ou} privada?

A acessibilidade dos espaços de lazer da Orla de Atalaia e a qualidade das estruturas são os fatores primordiais de atração das tribos à localidade, apesar de alguns contratempos para vencer a distância do local de origem dos freqüentadores (conforme os relatos, alguns frequentadores são das circunvizinhanças de Aracaju) e driblar os 
obstáculos da forma de administrar os equipamentos que compõem o complexo de lazer da Orla de Atalaia.

Percebemos que até mesmo quem é de Aracaju enfrenta dificuldades para usufruir os espaços de lazer, principalmente, devido ao sistema de transporte coletivo, porém é ainda mais desgastante para os moradores das localidades circunvizinhas. O trecho a seguir demonstra que a qualidade vence o desafio de chegar até lá.

[...] Fora o Ruan que é da Barra (cidade Barra dos Coqueiros). É o nosso goleiro, [...] ele tem que atravessar, mas o resto mora. Um mora no Cirurgia (bairro da capital), outro mora perto do Médici (bairro da capital), Luzia (bairro da capital) [...] Vem de moto, carro, carona. Tem gente que vem de ônibus, tem gente que vem de todo tipo (de transporte)... de bicicleta... (HO)

Devido à localidade ser mais fácil pra todos, [...], assim, onde a maioria reside não tem a quadra pra o esporte, né? E também a facilidade pra o espaço devido o horário que a gente tá vindo. (FS)

Encontramos aqui, nesses depoimentos, pontos importantes para reflexão acerca das contradições no tocante ao espaço público - destinado ao lazer - e a relação econômico-turística que se manifesta. Ora, por que os agentes públicos não desenvolvem políticas de reestruturação e/ou construção de quadras esportivas, dos parques e espaços de lazer nos bairros? Por que apenas a Orla foi "recheada" das melhorias estruturais de lazer e tornando-se um cartão postal do Estado?

Como constatamos em entrevista existem outras pistas de skates em outros bairros da cidade, os quais poderiam ser também de boa qualidade e de fácil acesso. Porém, não é o que acontece, pois segundo os entrevistados a maior parte dos equipamentos encontrados na orla não existe em outros bairros e quando essa presença é contemplada, a qualidade não se equipara. 
Obviamente que a dimensão econômica e política sobressai. As grandes corporações hoteleiras, bem como os bares e restaurantes estão localizados na Orla e, portanto, no mundo da estética da mercadoria (HAUG, 1997) e da sociedade do espetáculo (DEBORD, 1997) e preferível esconder os problemas nos próprios bairros, ou seja, deixar a "sujeira debaixo do tapete". Essa realidade pode ser percebida no próprio bairro que fica escondido atrás da parede de concreto formada pelas redes hoteleiras que se estendem ao longo da avenida principal da Orla.

Além disso, deparamos com outra contradição no tocante aos espaços públicos. Algumas instituições como o Serviço Especial do Comércio (SESC), a Federação Sergipana de Tênis (FST) e o Kartódromo de Sergipe são responsáveis pela manutenção de algumas áreas e em contrapartida arrebata o seu "pedaço no bolo" estipulando taxas para uso da população. Uma relação financeira que toca durante as entrevistas e que se dá em quatro momentos: o investimento do Estado, já que é uma obra governamental resultante da parceria do governo estadual e municipal (Aracaju-SE); o investimento que cada empresário mantém para suster as federações; o custo cobrado aos usuários esporádicos do equipamento (para manutenção do espaço); e, os investimentos de patrocinadores quando há realização de campeonatos ${ }^{19}$.

[...] É uma taxa simbólica pra manutenção [...] o gasto é muito grande (no campo socyte) com gramado, segurança, aí você tem uma taxa que não chega nem longe, que não tem nem como recuperar [...] comecei a olhar (a tabela de preços) [...] e tava, olhe, de 20 ou 25 reais para associados quando era à noite, $\mathrm{R} \$ 20,00$ de dia. Aí para quem não era comerciário cobrava $\mathrm{R} \$ 40,00$, mesmo assim, 1 hora e meia o cara junta aí um grupo e faz uma cota. (AS)

\footnotetext{
${ }^{19}$ Tivemos a oportunidade de entrevistar o jornalista da TV Cidade, o qual afirmou que a emissora estava sendo remunerada para fazer a cobertura da final do Campeonato Sergipano de Kart, mas também acrescenta que “... na parte financeira no momento em que você tá transmitindo você consegue patrocinadores, então quem tá bancando na verdade é (sic) os patrocinadores." Porém não fala dos patrocinadores nem das cifras em questão. Entrevista realizada em dezembro de 2008 na final do Campeonato Sergipano de Kart.
} 
O kart hoje 20 minutos você paga 15 a 20 reais, aí você recebe capacete com macacão, luva, você vem, participa [...], qualquer pessoa pode ter acesso, é um kart que tem proteção, não tem perigo nenhum de você bater e se machucar. (KA)

Portanto, a acessibilidade não é tão gratuita, visto que, algumas modalidades e espaços esportivos cobram taxas de acesso garantindo a seletividade das pessoas, em contrapartida do "equivalente geral" válido para o complexo Orla. Por ser livre e gratuito para todas as pessoas possibilita o encontro entre todos, inclusive àqueles que fazem uso dos espaços restritos, porém, estabelece uma relação mercadológica não quando o acesso é a todos, mas a poucos.

\section{As práticas corporais de lazer e as implicações do universo capitalista}

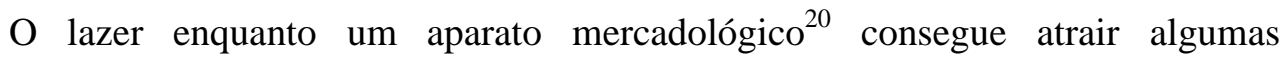
instituições empresariais em busca do prazer dos poucos usuários, a exemplo dos corredores de kart.

No kartódromo, ocorrem campeonatos anuais, amistosos e treinos constantes, contudo, somente a paixão pela prática não proporciona a satisfação de utilizar um kart, correr na pista. Em entrevista ao corredor e presidente da Associação Sergipana de Kart (na época), identificamos algumas nuances que nos fazem pensar até que ponto o espaço público de lazer é de fato "público" em prol do lazer de todos os tipos de pessoas que frequentam a Orla.

Hoje tem pessoas que tem poucas condições e tão no kart. O investimento pra tá numa corrida você gasta de 300 a 400 reais por mês, não é muito em relação ao que você se distrai. (KA)

\footnotetext{
${ }^{20}$ Ver Dumazedier, Sociologia Empírica do Lazer (1974).
} 
Que sentido podemos atribuir ao termo "condições" neste caso? A que condições o entrevistado está se referindo? Seria de um pai de família que tem que sustentar mulher e filhos, ganhando mensalmente a mesma quantia que alguém que pode investir na utilização do kartódromo para curtir o seu tempo de lazer? Ou mesmo as condições escassas dos meninos da tribo da bike, que sonham em ser atletas com uma BMX (Bike Moto Cross) e ainda se contentam em ter uma bicicleta de valores altos para seus poucos recursos, mas valores irrisórios para os empresários do kart.

Eu queria ser Cross, eu gastei 50 reais nessa aí e vou gastar mais 50 reais pra botar raio inox e janta aérea e... E a minha tem documento. (BC)

Também queria ser Cross (BMX). Eu comprei a minha bicicleta por 30 reais. (BC)

Pode-se perceber que é grande a movimentação financeira exigida dos usuários para manutenção e conservação da estrutura, tanto no cotidiano e em eventos especiais como campeonatos, que vem atraindo a cobertura jornalística (ano de 2008, etapa final transmitida ao vivo):

[...] Nós temos algumas empresas que estão investindo no kart, mas na maioria são empresas dos próprios empresários, os pilotos aqui a maioria são empresários. Então, cada um banca seu kart, põe o nome da sua empresa [...] A nossa idéia é no próximo ano [...] vendermos as etapas (do campeonato), por exemplo, são dez etapas, a gente faria o seguinte, "1" etapa- Etapa Coca-cola de Kart", então, a coca-cola viria pagaria um valor, esse valor seria subsidiado para a associação, né? E seria distribuído em forma de recursos para os pilotos [...] Nós fizemos o convite, foi estabelecida uma cota, valores. A minha empresa comprou uma cota, por exemplo, foi $\mathrm{R} \$ 1000$, aí duas ou três empresas de outras pessoas aqui também compraram uma cota. Ela (a empresa televisiva) não veio de graça não. (KA)

Percebemos, então, no tocante ao Kart, que vai mais além da vontade de brincar com aqueles carrinhos velozes. É preciso disponibilizar uma boa quantia em dinheiro 
para acessá-los, bem como a ótica que perpassa os "bastidores" é a ótica do capital, da circulação do dinheiro e principalmente, do lucro.

Outro destaque é a aproximação das pessoas mediante o vínculo empregatício. Em uma das situações de visita a ponto de observação foi descoberta a tribo do futebol, constituída por pessoas que fazem parte de uma mesma empresa.

Podemos reportar este recorte ao lazer como criação forçada da sociedade capitalista, na qual ele é entendido como atividade que mascara a manipulação da empresa sobre o horário de trabalho dos seus empregados ${ }^{21}$. Os trabalhadores são induzidos a conduzir o tempo de lazer de acordo com o que lhes proporciona a empresa, que nada mais é do que um modo de manipulá-los. Lembrando que não é à toa o incentivo à prática, que é uma "paixão nacional”, por assim dizer.

[...] o ideal seria pra gente o futebol, mas devido à quantidade de gente não é suficiente para o futebol, aí escolhemos (o futsal) [...]. É uma peladinha, bem dizendo, só que é disputa, né? Uma loja contra a outra, entendeu? (FS)

O uniforme, assim, o uniforme é dado pela empresa, que a empresa cede pra gente. A gente pega e vem jogar aqui, né? Como aqui mesmo tinha nas lojas, cada loja tinha um diferente desse aqui (uniforme), era campo antes, era uma loja disputando com a outra como se tivesse um campeonato. Tinha um presente para o time que ganhasse, mas isso acabou. (FS)

Eles unem o útil ao agradável, praticam a tão cobiçada "paixão nacional", ganham os dois incentivos que complementam a vontade de jogar, vestimenta e premiação, e ainda por cima se divertem. E a empresa lucra com o conveniente, pois ao incentivar a prática esportiva diminui os custos com profissionais de ginástica laboral e obtém isenção de ter que diminuir a carga horária dos empregados e aumentar o tempo

${ }^{21}$ Ver Dumazedier, Sociologia Empírica do Lazer (1974). 
livre para que eles possam ter um tempo de lazer maior, de mais qualidade, sem orientação ou indicação e sem precisar de incentivo.

É curioso notar que o hábito dos jogadores não cessou mesmo que a empresa não tenha mais incentivado nenhuma competição, eles tornaram-se "jogadores de final de semana", consolidaram uma amizade, mas continuam jogando com o uniforme da empresa.

\section{CONSIDERAÇÕES FINAIS}

Orla de Atalaia, cenário onde atuam um sem número de tribos em busca de um momento de lazer, de diversão, de entretenimento, com gostos e estilos ora diferentes, ora comuns, torna-se para nós pesquisadores um verdadeiro "Ponto de Observação".

Um parêntese para o tempo de lazer, ou seria para o tempo ocioso, o tempo do não-trabalho? Seja qual for destas opções, a finalidade do treino ou da diversão movem todas as tribos em direção ao Complexo de Lazer Orla de Atalaia sem, contudo, questionar porque são obrigadas a se deslocar, muitas vezes de locais distantes, e ainda pagar para usufruir, ou fazê-lo em condições precárias quando não existe taxa de acesso. Neste ponto seria importante rever como está sendo tratado o âmbito das políticas públicas em relação ao atendimento de qualidade das comunidades no que tange a estruturas adequadas e acessíveis nos bairros mais distantes em relação ao bairro Atalaia onde fica localizado o Complexo Orla.

Frisamos que em visitas posteriores aos equipamentos nos fizeram recordar que durante o período de observação o Skatepark esteve em péssimo estado de conservação em se tratando de pintura, limpeza e iluminação, no entanto, nas visitas no ano de 2011 novas pinturas foram feitas unicamente com o estilo grafitagem, com formas mais 
coloridas e sem nomes específicos, diferente das gravuras encontradas nos períodos anteriores, que por um determinado tempo da pesquisa esteve sem pintura alguma. Os demais espaços foram reformados, ainda assim, o kartódromo se destaca com seu alto padrão de conservação.

Notamos que há relação de proximidade com o espaço e com os companheiros de mesmo grupo, das "tribos", um momento entre amigos, um espaço oportuno à aceitação dos modos "de ser e de estar" do exótico, daquele que no sentido puro da palavra é "ex", fora da ótica comum da sociedade, de acordo com Pais (2004). Porém, a relação entre as próprias tribos é por vezes conflitante, não existindo relações de proximidades entre elas, mesmo as tribos dos skatistas, patinadores e bicicleteiros que obrigatoriamente ocupam o mesmo equipamento, cada uma vivendo em seu mundo e ocupando o mesmo espaço.

Concluímos que a cobrança pelo acesso a cada equipamento de lazer garante a poucos a qualidade do ambiente, gerando controvérsias no complexo público. As nossas análises mostram claramente que os espaços onde normalmente são acessados com taxas possuem uma infra-estrutura conservada por mais tempo, são constantemente vigiados e tem um público espectador com características de pessoas de classes mais abastadas $^{22}$, pois, de acordo com as observações, principalmente no kartódromo, esses espectadores eram grupos formados por familiares e amigos dos pilotos. Assim, essa característica parece mascarar uma parte que não comunga com o todo.

No entanto, percebe-se que os espaços da Orla de Atalaia estão sendo ocupado por grupos que tem uma relação de amor, satisfação ou paixão, explicado por eles. Homens em sua maioria, mas também mulheres que aderem à prática corporal com a

\footnotetext{
${ }^{22}$ Esse público não se refere às tribos, mas àqueles que apreciam a prática do kart, em especial. Pois, nos demais equipamentos utilizados pelas outras tribos não encontramos muitos espectadores, a não ser alguns transeuntes curiosos.
} 
qual se identificam. Este aspecto garante uma relação de proximidade e identidade entre as tribos e os seus equipamentos, mesmo quando integram mundos tão distantes, separados pelo fator capital.

\section{REFERÊNCIAS}

BOURDIEU, P. O Poder Simbólico. Rio de Janeiro: Bertrand Brasil, 2007.

CHAUÍ, M. Convite à Filosofia. São Paulo: Ática, 2006.

COSTA, A. G.; PIRES, G. De L. Moda/indumentária em culturas juvenis: símbolos de comunicação e formação de identidades corporais provisórias em jovens de ensino médio. In: CONGRESSO SUL BRASILEIRO DE CIÊNCIAS DO ESPORTE, 3, 2006, Santa Maria/RS. Anais eletrônicos... Santa Maria: CBCE-RS, set/2006.

DEBORD, G. A Sociedade do Espetáculo. Rio de Janeiro: Contraponto, 1997.

DUMAZEDIER, J. Sociologia Empírica do Lazer. São Paulo: Perspectiva, 1974.

FERREIRA, A. B. de H. Miniaurélio Século XXI Escolar: o minidicionário da língua portuguesa. Rio de Janeiro: Nova Fronteira, 2001.

GOELLNER, S. V.; et al. Gênero e raça: inclusão no esporte e lazer. Porto Alegre: UFRGS, 2009.

et al. Pesquisa qualitativa na Educação Física brasileira: marco teórico e modos

de usar. Revista da Educação Física/UEM. Maringá, v. 21, n. 3, p.1-30, 2010.

HACK, C.; PIRES, G. De L.. Lazer e mídia no cotidiano juvenil. In: ENCONTRO NACIONAL DE RECREAÇÃO E LAZER, 17, 2005, Campo Grande/MS. Anais eletrônicos... Campo Grande/MS: nov/2005.

HAUG, W. F. Crítica da Estética da Mercadoria. São Paulo: UNESP, 1997.

MARCELlinO, N. C. (Org). Lazer e Cultura. Campinas: Alínea, 2007.

MINAYO, M. C. de S. Pesquisa social: teoria, método e criatividade. Petrópolis: Vozes, 2007.

PAIS, J. M. Tribos Urbanas: produções artísticas e identidades. São Paulo: Annablume, 2004.

PIRES, G. De L. Educação Física e o discurso midiático: abordagem críticoemancipatória. Ijuí: Unijuí, 2002. 
RIBEIRO, S. et al. MCSL - Lazer, Comunidade e Universidade: registro de uma ocupação pacífica. In: ENCONTRO NACIONAL DE RECREAÇÃO E LAZER, 15, 2003. Anais..., Santo André/SP: 2003.

TRIVIÑOS, A. N. S. Introdução à pesquisa em ciências sociais: a pesquisa qualitativa em educação. São Paulo: Atlas, 2006.

http://www.skatistaonline.com/category/cidade/aracaju, acesso em 30 de março de 2011.

\section{Endereço dos Autores:}

Paula Aragão

Rua Júlio Dácia Barreto, 191, casa C

Bairro Saco dos Limões

Florianópolis - SC - CEP: 88040-520

Endereço Eletrônico: aragao_paula@hotmail.com 